\title{
Heat flow and heat transfer coefficient during crystallization under the pressure
}

\author{
Richard Pastirčák ${ }^{1, *}$, Ján Ščury ${ }^{1}$, Tomáš Fecura ${ }^{1}$ \\ Department of technological engineering, University of Žilina, Univerzitná 8215/1, 01026 Žilina
}

\begin{abstract}
Estimation of the heat flow at the metal-mold interface is necessary for accurate simulation of the solidification processes. For the numerical simulation, a precise prediction of boundary conditions is required to determine the temperature distribution during solidification, porosity nucleation, microstructure development, and residual stresses. Determination of the heat transfer coefficients at the metal-mold interface is a critical aspect for simulation of the solidification process and the microstructure modeling of the castings. For crystallization under the pressure and for thin-walled castings, HTC evaluation is important due to the very limited freezing time.
\end{abstract}

Keywords: Squeeze casting, HTC, Heat flow, Pressure.

\section{Introduction}

All the thermal phenomenons in the casting-mold system are very closely related to the release and transfer of heat during solidification and cooling of the casting. The rate of heat transfer is very important to determine the solidification time and the distribution of temperature fields throughout the system. It also directly and indirectly affects the resulting microstructure, and thus the quality and properties of the future casting $[1,3,4]$.

The heat flow between the casting, mold, and surrounding environment is from the initial contact of the melt with the mold up to his complete cooling a non-stationary phenomenon. In non-stationary thermal processes, the thermal content of the solid is changing. The heat content of the casting decreases and the mold rises until the heat contents and temperatures are balanced. The change rate of the thermal content of the solid, the rate of isotherm process and temperature equalization is directly proportional to his thermal conductivity $\lambda$ and inversely proportional thermal-capacity cabability c. $\rho$. $[1,2,5,6]$.

The heat flow at the interface between the mold and the casting directly influences the solidification process and plays an important role in determining the solidification conditions of the casting metal. In the process of the casting under pressure, the casting quality is directly affected by the transfer of heat to the casting-mold interface, where the amount of heat transferred from the casting to the mold is changing over time. By creating an air gap at the casting-mold interface during solidification, the value of the heat transfer

\footnotetext{
*Corresponding author: richard.pastircak@fstroj.uniza.sk

Reviewers: Františka Pešlová, Wieslawa Piekarska
} 
coefficient decreases. The change of heat transfer coefficient by the casting time is a key factor for controlling solidification. The value of this coefficient is influenced in particular by the heat-physical properties of the materials, the temperature of the mold, the temperature of the metal, the working pressure, the casting geometry, the roughness of the mold surface and the protective coating of the mold $[3,7,8,10]$.

The squeeze casting technology, which was used in experimental verification of the heat transfer is a relatively unusual method. This is due, in particular, to little experience with practical use combined with the low lifetime of the mold. The pressure value for squeeze casting is from 30 to $150 \mathrm{MPa}$. The pressure itself prevents the formation of an air gap which normally formed during gravity casting at the interface between the casting and the mold. By eliminating this air gap, there is a significant increase of the heat transfer and the heat flow from the casting into the mold. The melt and later the casting itself is constantly in contact with the walls of the metal mold, which resulting in a significant increase the rate of solidification and cooling of the casting. The result is a change of the structure and mechanical properties of the casting. In The structure, the grains size of the primary structure is reduces and also is change the morphology of eutectic silicon and intermetallic phases, which act less harmful. The resulting structure is finer and more uniform throughout the volume. The concentration of silicon in the eutectic and the volume ratio of the primary $\alpha$-phase are increased and the volume of the eutectic in the structure is reduced. The result is a change in mechanical properties, where the strength, elongation and fracture toughness are increasing $[2,4,9,10]$.

\section{Experimental material and process}

For experimental casting, direct squeeze casting method was used. Precisely measured dose of the liquid metal was poured into the mold cavity. The mold was machined from low carbon steel. The surface of the mold cavity and the plunger has been treated with a protective paint type Terracotta. The liquid melt was pressed by using a plunger which section area was $1000 \mathrm{~mm} 2$. The onset of action was approximately 8 seconds by filling mold. The sample was under pressure until the cooling of the melt to $200{ }^{\circ} \mathrm{C}$. During the experiment was casted 4 samples at various temperatures and the applied casting pressure. The casting parameters are listed in Tab. 1 . The first sample was cast by gravity casting at a temperature of $710{ }^{\circ} \mathrm{C}$. Further samples were cast under pressure by using technology squeeze casting. In both cases the metal mold was preheated to $100{ }^{\circ} \mathrm{C}$. For measuring the temperature of the melt and mold 8 thermocouples type $\mathrm{K}$ were used, with a wire Do $=0.25$ $\mathrm{mm}$ in order to respond rapidly. Position of the thermocouples is shown in Fig. 1.

Table 1. Casting parameters for individual samples

\begin{tabular}{|c|c|c|c|}
\hline \hline sample & $\begin{array}{c}\text { pressure } \\
{[\mathbf{M P a}]}\end{array}$ & $\begin{array}{c}\text { casting temperature } \\
{\left[{ }^{\circ} \mathbf{C}\right]}\end{array}$ & $\begin{array}{c}\text { mold temperature } \\
{\left[{ }^{\circ} \mathbf{C}\right]}\end{array}$ \\
\hline $\mathbf{1}$ & 0.1 & $710 \pm 5$ & $20 \pm 3$ \\
\hline $\mathbf{2}$ & 50 & $710 \pm 5$ & $100 \pm 3$ \\
\hline $\mathbf{3}$ & 100 & $710 \pm 5$ & $100 \pm 3$ \\
\hline $\mathbf{4}$ & 150 & $710 \pm 5$ & $100 \pm 3$ \\
\hline
\end{tabular}



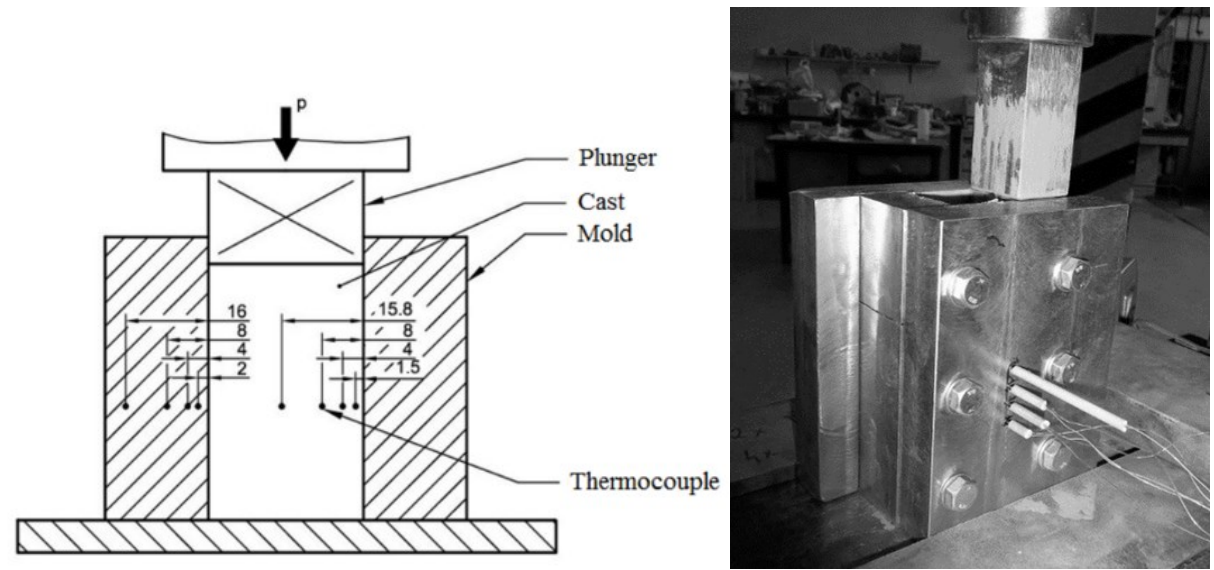

Fig. 1. Principle of thermocouples distribution

The governing heat transfer equation in one-dimensional coordinates is given by equation (1):

$$
\rho c_{\mathrm{p}} \frac{\partial T}{\partial t}=\frac{\partial}{\partial x}\left(\lambda \frac{\partial T}{\partial x}\right)
$$

The heat flux on the interface cast-mold can be calculated from the temperature gradient on the surface and the subsurface layer using the equation (2):

$$
q=-\lambda \frac{\partial T}{\partial x} 5=-\lambda \frac{T_{1}-T_{2}}{\Delta x}
$$

where $\lambda$ is thermal conductivity from the casting to the mold. $T_{1,2}$ are temperatures of the measured points and $\Delta \mathrm{x}$ is the distance between these points.

The average heat transfer coefficient HTC at the interphase may be expressed mathematically (3):

$$
H T C=\frac{q}{\left(T_{O^{-}}-T_{F}\right)}
$$

where $T_{O}$ is temperature casting surface, $T_{F}$ is temperature mold surface.

The alloy $\mathrm{AlCu} 4 \mathrm{Ti}$ was used for the experiment. Regarding this alloy, a significant solidification front should not occur, and also a wide freezing interval provides a sufficiently long period of time to initiate the pressure action during the time of the alloy crystallization. This alloy was therefore suitable for detecting the heat flow from the cast into the mold. The chemical composition of the AlCu4Ti alloy is shown in Table 2.

Table 2. The chemical composition of the experimental alloy $\mathrm{AlCu} 4 \mathrm{Ti}$

\begin{tabular}{|l|c|c|c|c|c|c|c|}
\hline Element & $\mathbf{S i}$ & $\mathbf{C u}$ & $\mathbf{M g}$ & $\mathbf{N i}$ & $\mathbf{S n}$ & $\mathbf{P}$ & $\mathbf{S b}$ \\
\hline [at. \%] & 0.05 & 4.612 & 0.005 & 0.006 & 0.025 & 0.0005 & 0.00463 \\
\hline Element & $\mathbf{T i}$ & $\mathbf{F e}$ & $\mathbf{M n}$ & $\mathbf{N a}$ & $\mathbf{Z n}$ & $\mathbf{Z r}$ & $\mathbf{P b}$ \\
\hline [at. \%] & 0.171 & 0.127 & 0.456 & 0.0001 & 0.008 & 0.001 & 0.002 \\
\hline
\end{tabular}




\section{Results}

The measured values were processed in a tabular processor Microsoft Excel. From the measured curves of temperature in casting and mold, temperature on the surface of the mold and casting was estimated. In individual time points was by using the regression curve determined an identified temperature in the zero distance from the surface. Principle of evaluation is shown in Fig.2-3.

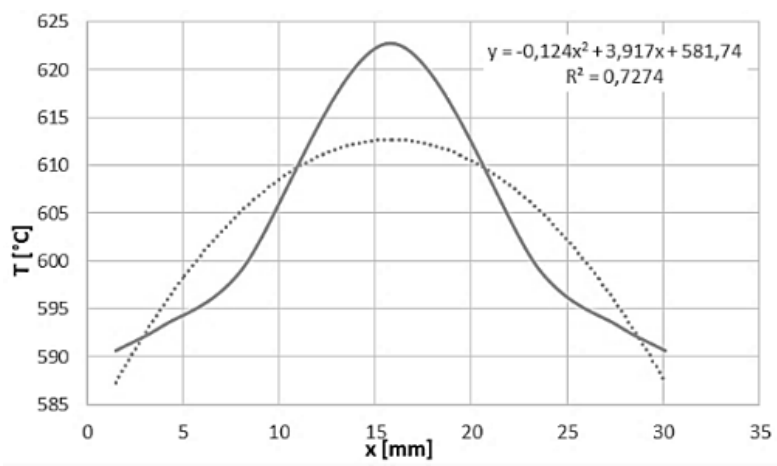

Fig. 2. The fundamentals of determining the surface temperature of the casting by regression curves

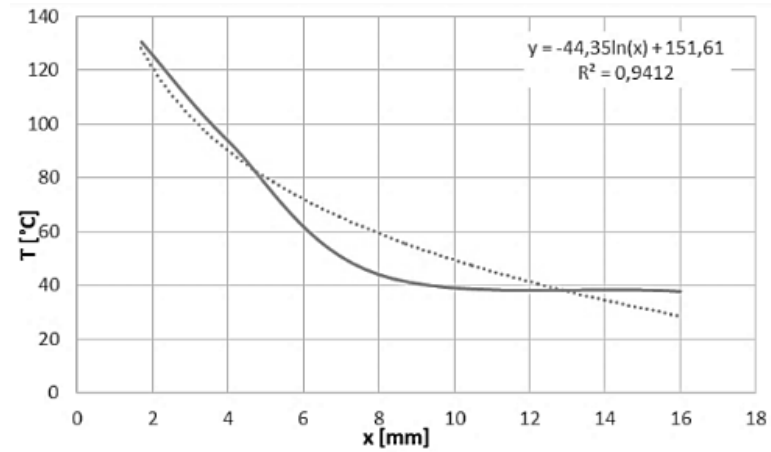

Fig. 3. The fundamentals of determining the surface temperature of the mold by regression curves

In Fig. 4 is shown the course of the temperatures at the casting without pressure.

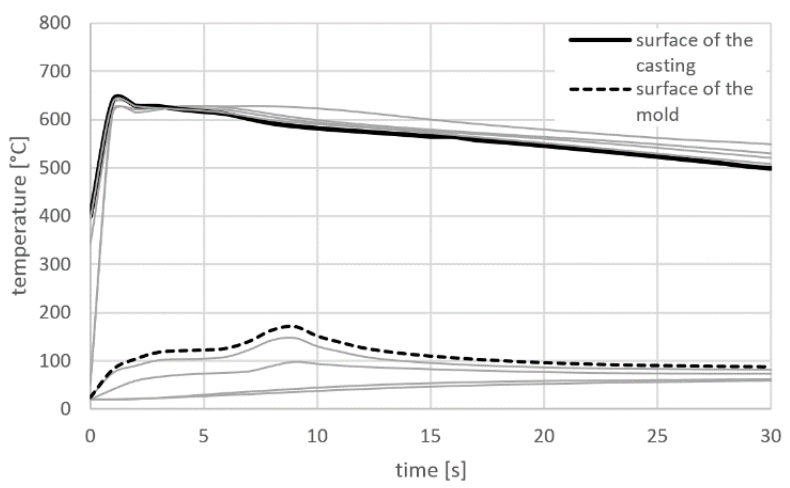

Fig. 4. Temperatures in the casting and in the mold at the gravity casting 
In Fig. 5-7 is shown the course of the temperatures with using squeeze casting technology.

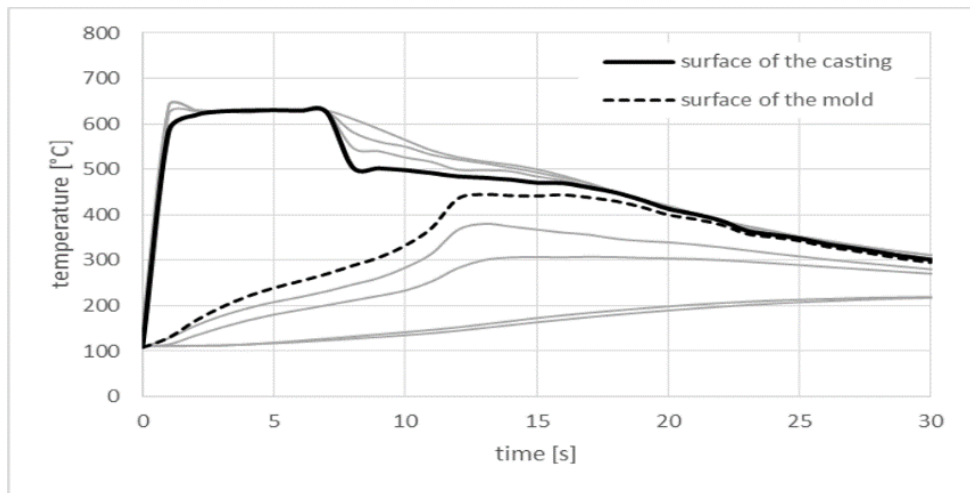

Fig. 5. The temperatures in the casting and in the mold at the operating pressure $50 \mathrm{MPa}$

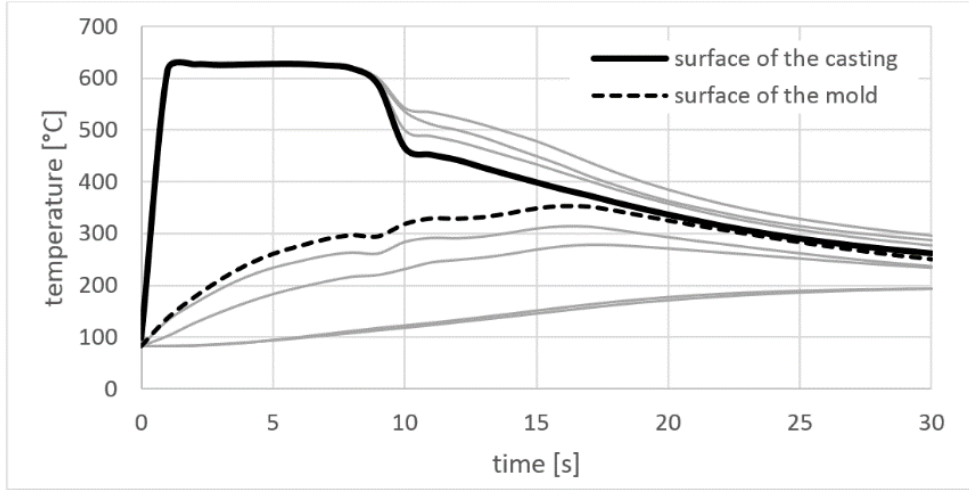

Fig. 6. The temperatures in the casting and in the mold at the operating pressure $100 \mathrm{MPa}$

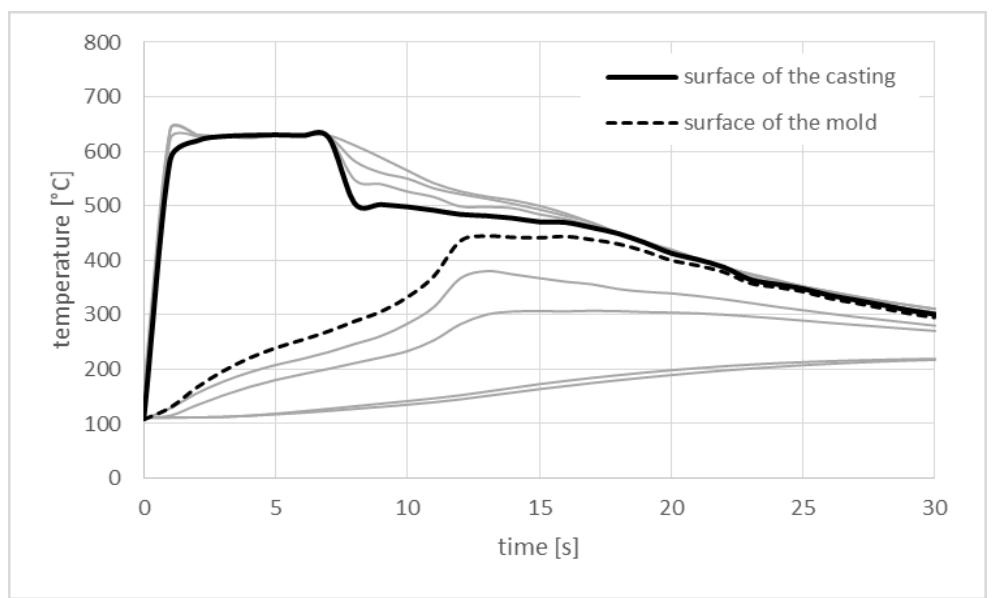

Fig. 7. The temperatures in the casting and in the mold at the operating pressure $150 \mathrm{MPa}$ 


\subsection{Heat flux and heat transfer coefficient}

The heat flux on the interface between casting and mold was determined from temperatures on the surface of a mold and temperatures $2 \mathrm{~mm}$ under the surface by the equation (1). The results of HTC were calculated by the equation (2). The course of heat flux and HTC for each sample is shown on the figures 8-11.

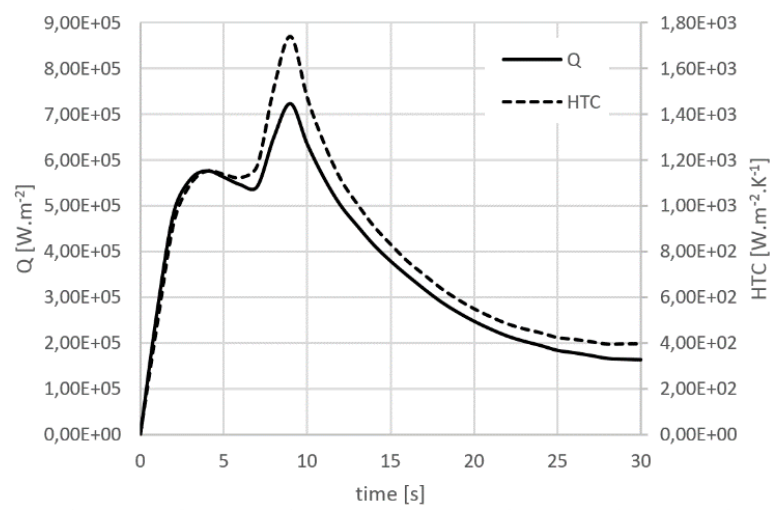

Fig. 8. Heat flux and HTC in gravity casting at pouring temperature $710{ }^{\circ} \mathrm{C}$

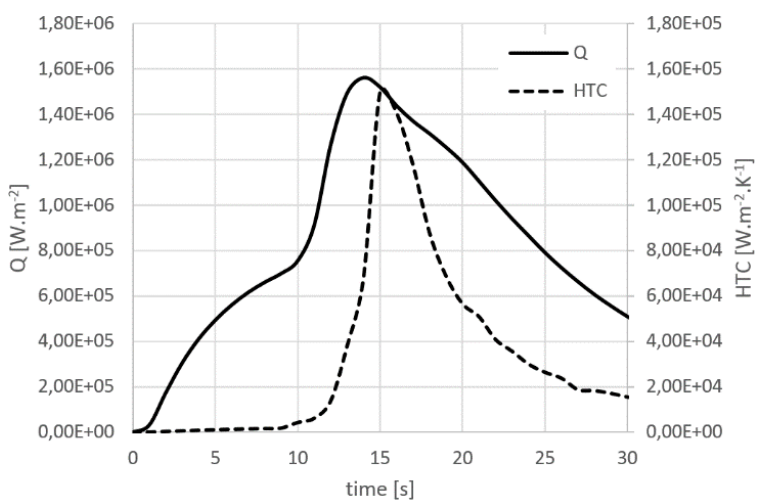

Fig. 9. Heat flux and $\mathrm{HTC}$ at pouring temperature $710^{\circ} \mathrm{C}$ and pressure $50 \mathrm{MPa}$

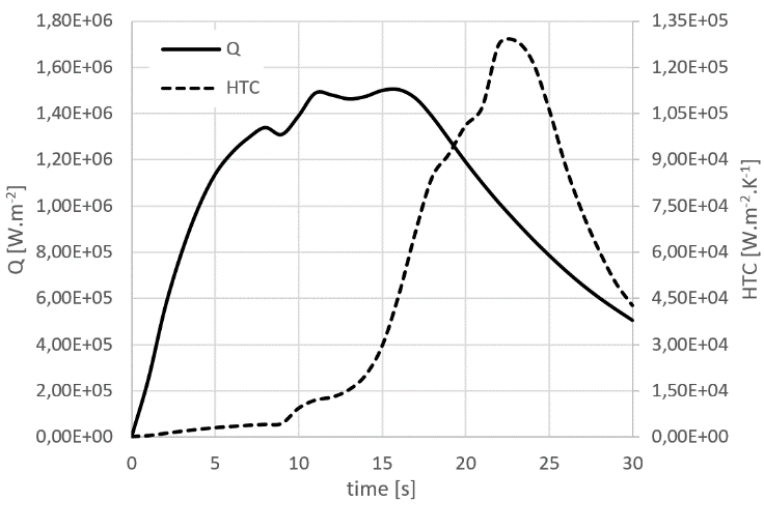

Fig. 10. Heat flux and $\mathrm{HTC}$ at pouring temperature $710^{\circ} \mathrm{C}$ and pressure $100 \mathrm{MPa}$ 


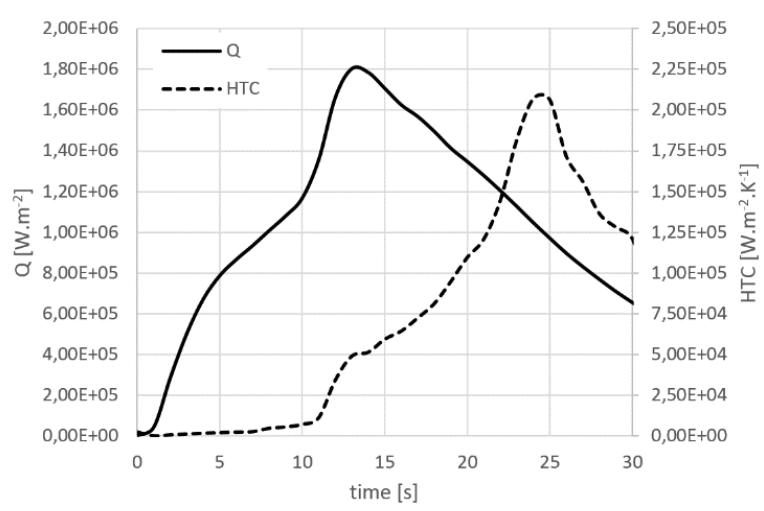

Fig. 11. Heat flux and $\mathrm{HTC}$ at pouring temperature $710{ }^{\circ} \mathrm{C}$ and pressure $150 \mathrm{MPa}$

From the results of the measurements it is clear, that there has been a significant increase of the heat flow and the heat transfer coefficient, which result was in faster cooling of the casting. The amount of heat $Q$ that passes through the isothermal surface $S$ is defined by multiplying the heat flux $q$ and time $\tau$

$$
Q=q \cdot S \cdot \tau
$$

The amount of heat that has been cast from the cast into the mold for 30 seconds is shown in fig. 12.

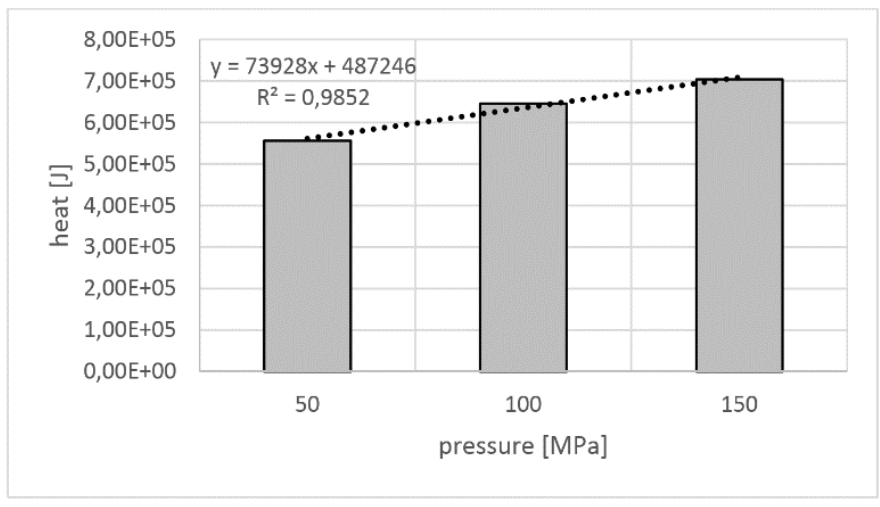

Fig. 12. Amount of heat transmitted to the casting

\section{Conclusions}

Heat flux in the gravity cast sample increased within 5 seconds after pouring. Shrinking of the casting resulted in the formation of a gap at the casting-mold interface. The formed gap caused reduced heat flux from the casting. In the unaffected sample, the heat flux at the onset of pouring increased to the value of $5.75 .10^{5} \mathrm{~W} . \mathrm{m}^{-2}$. At time 7 seconds after pouring, heat flux through the gap started to apply. The heat flux value increased up to $7.22 .10^{5} \mathrm{~W} \cdot \mathrm{m}^{-2}$. Heat transfer coefficient reached the value of $1.15 \cdot 10^{3} \mathrm{~W} \cdot \mathrm{m}^{-2} \cdot \mathrm{K}^{-1}$ at the onset of pouring, only to increase to the value of $1.74 .10^{3} \mathrm{~W} \cdot \mathrm{m}^{-2} \cdot \mathrm{K}^{-1}$ when applying heat transfer through the gap. For technological reasons, pressure was applied 8 seconds after filling the mold. All samples affected by pressure experienced a significant increase in both the heat flux and heat transfer coefficient at the casting-mold interface. At the casting temperature of $710^{\circ} \mathrm{C}$, the increase in $\mathrm{HTC}$ was 187 -fold at $50 \mathrm{MPa}, 317$-fold at $100 \mathrm{MPa}$, 
and 525-fold at $150 \mathrm{MPa}$. Heat transfer at the casting-mold interface significantly increases with the increasing difference in heat contents of the poured material and the mold, and also with the increasing applied pressure.

It was observed the amount of heat that has passed into the casting mold. A direct relationship between the amount of heat and the applied pressure was observed.

This work was created in the framework of the grant projekt VEGA $N^{\circ} 1 / 0494 / 17$. The authors acknowledge the grant agency for support.

\section{References}

1. A. F. Ilkhchy, M. Jabbari, P. Davami, Effect of pressure on heat transfer coefficient of A356 aluminium alloy. [online] [cited by 2016-03-08] ISSN 0735-1933, http://www.sciencedirect.com/science/article/pii/S0735193312000711, (2012)

2. J. O. Aweda, M. B. Adeyemi, Experimental determination of heat transfer coefficients during squeeze casting of aluminium. Journal of Materials Processing Technology 209 (3), 1477-1483 (2009)

3. R. Pastirčák, J. Ščury, M. Brůna, D. Bolibruchová, Effect of Technological Parameters on the AlSi12 Alloy Microstructure During Crystallization Under Pressure. Archives of foundry engineering 17 (2), 75-78 (2017)

4. R. Pastirčák, J. Ščury, Effect of technological parameters on microstructure in alloy AlCu4Ti using squeeze casting. American Institute of Physics Publising, AIP conference proceedings 1745 (2016)

5. A. Iyer, Squeeze casting: The future. [online]. [cited by 2017-02-11] http://issinstitute.org.au/wp-content/media/2011/05/ISS-FEL-REPORT-A-IYER-lowres.pdf (2011)

6. D. Bolibruchová, J. Macko, M. Brůna, Elimination of negative effect of $\mathrm{Fe}$ in secondary alloys AlSi6Cu4 (EN AC 45 000, A 319) by nickel. Archives of metallurgy and materials 59 (2), 717-721 (2014)

7. P. Pecháč, M. Sága, Controlling of local search methods' parameters in memetic algorithms using the principles of simulated annealing. Procedia Engineering 136, 70-76 (2016)

8. D. Bolibruchová, L. Richtarech, S.M. Dobosz, K. Major-Gabrys, Utilisation of Mould Temperature Change in Eliminating the AlsFeSI Phases in Secondary AlSi7Mg0.3 Alloy. Archives of Metallurgy and Materials 62 (1), 357-362 (2017)

9. P. Kopas, L. Jakubovičová, M. Vaško, M. Handrik, Fatigue resistance of reinforcing steel bars. Procedia Engineering 136, 193-197 (2016)

10. R. Koňar, M. Mičian, Ultrasonic Inspection Techniques Possibilities for Centrifugal Cast Copper Alloy. Archives of foundry engineering 17 (2), 35-38 (2017) 